\title{
La interactividad como arte
}

\section{Interactivity as art}

\author{
Ignacio Vázquez Zapata
}

Profesor Depatamento de Tecnología

(Escuela superior de Diseño de Madrid)

Fecha de recepción: 23 de octubre de 2014

Fecha de revisión: 21 de enero de 2015

Para citar este artículo: Vázquez Zapata, I. (2015): La interactividad como arte, Icono 14, volumen (13), pp. 270-293. doi: 10.7195/ri14.v13i1.754 


\section{Resumen}

Desde los inicios del siglo XX la tecnología ha tenido una influencia creciente sobre la actividad artística y la expresión creativa. En la era digital la tecnología ha abierto a muchos artistas y técnicos la posibilidad de realizar obras en las que la interactividad constituye el componente fundamental de la obra. La relación entre la obra y el espectador debe ser inmediata, espectacular y comprensible, los artistas trabajan fundamentalmente con sistemas basados en el espejo, el eco y el aumento de la potencia.

\section{Palabras clave}

Interactividad - Arte digital - Tecnología - Expresión

\section{Abstract}

Since the early twentieth century technology has had a growing influence on the artistic activity and creative expression. In digital age, technology has opened many artists and technicians the opportunity to perform works that interactivity is the key part of the work. The relationship between the work and the viewer should be immediate, dramatic and understandable, artists work mainly with based in the mirror, echo and increase in power systems.

\section{Key Words}

Interactivity - Digital art - Technology - Expression

\section{Introducción}

El propósito de la obra de arte ha sido siempre generar experiencias, percepciones o actitudes estéticas. Desde los inicios del siglo XX las vanguardias buscaron nuevas formas artísticas mediante diversas formas de interacción que permitieran una relación más intensa con el espectador. Los creadores vieron en los avances tecnológicos posibilidades expresivas que abrían el camino a innovadoras tipologías artísticas.

ICONO14 | Año 2015 Volumen $13 N^{\circ} 1$ | ISSN: 1697-8293 | DOI: ri14.v13i1.754 
Los artistas de Fluxus impulsaron la poética de lo aleatorio y anticiparon muchas de las características del arte interactivo actual. Nam June Paik, uno de sus miembros, afirmaba que estaban creando un nuevo tipo de lienzo mediante pinceles que incorporaban todo tipo de innovaciones ${ }^{1}$. Para Bill Viola el vídeo hizo posible que el tiempo se incorporase a la pintura y pudiera crear lenguajes más complejos.

En la actualidad la interacción y la aleatoriedad son los paradigmas de nuevas formas de arte que trasladan al espectador el sentido de la obra. En este concepto de obra abierta apuntado por Umberto Eco, el significado depende no tanto del emisor como del destinatario que interpreta las señales y les confiere su verdadero sentido ${ }^{2}$.

Al principio, la interactividad se materializaba esencialmente en artefactos que invitaban a los usuarios a la observación y la manipulación. En las últimas décadas, el uso de la tecnología digital para la experimentación plástica ha dado pie a nuevas y complejas formas de expresión. La realidad virtual ha permitido la creación de entornos ficticios susceptibles de ser manipulados por el usuario. El hipertexto del lenguaje HTML ha servido para incorporar elementos narrativos en una experiencia multimedia que ha convertido a Internet en un paraguas capaz de cobijar numerosas manifestaciones artísticas personales o colaborativas. El futuro del arte aparece, por tanto, ligado a la evolución de la tecnología y a su dimensión esencialmente interactiva. Para el artista, el código es el lenguaje de este tiempo nuevo $^{3}$. La gran revolución del software libre ha permitido que aparezcan en la red comunidades muy activas con la intención de que el conocimiento sea público y accesible. De esta forma los artistas tienen la posibilidad de beneficiarse de las experiencias de otros y pueden poner en marcha propuestas colaborativas cada vez más complejas.

El artista ocupa una posición privilegiada para aportar nuevos sentidos a la tecnología. En los últimos años los grandes avances en los modos de interactuar han hecho que el ratón ya no sea suficiente para generar efectos de inmersión. Para muestra basta ver las campañas de lanzamiento de las consolas cuyo éxito reside en una manera de interactuar que permite una actividad más inmersiva y absorbente.

DOI: ri14.v13i1.754 | ISSN: 1697-8293 | Año 2015 Volumen 13 Nº 1 | ICONO14 


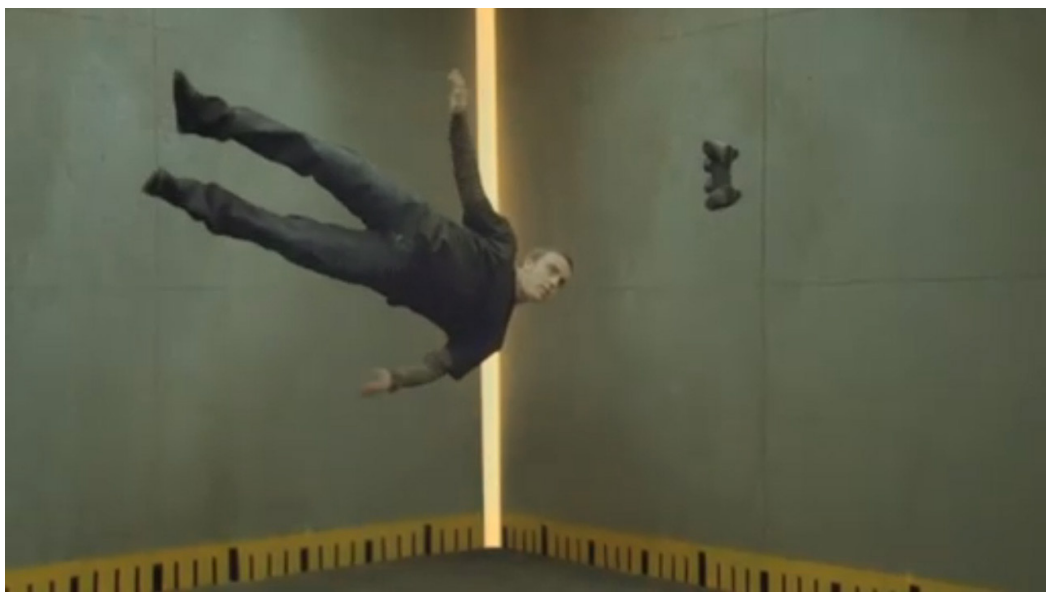

Figura 1: Fernando Alonso en la campaña de televisión para el lanzamiento de la consola de Sony y su nuevo mando Six Axis. ¿Cuál es el mundo real y cuál el virtual?. Imagen tomada de tvspotblog,com (http://www.dailymotion.com/video/k5bM7fuSegTkMxaOkH Vimeo)

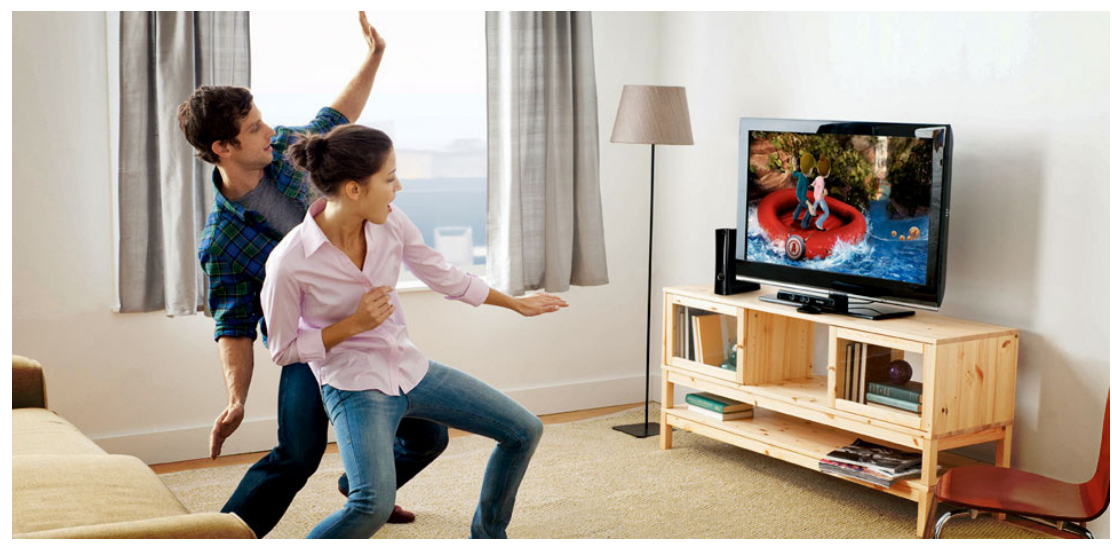

Figura 2: La interfaz Kinect para la consola Vbox 360 y el mensaje "tú eres el mando". Imagen tomada de xbox.com. (https://www.youtube.com/watch?v=uM4HOJf9mHO Youtube

Tirar piedras en un lago produce satisfacción. Una vez que has tirado piedras pequeñas, pasas a experimentar con otras más grandes que producen olas mayores y después, a tirar varias a la vez para contemplar cómo chocan las olas formadas por unas y otras. Varía la textura del agua, el color o el ruido, el resultado es cada vez más complejo pero su interacción igual de sencilla. 
La interacción puede producir efectos tan absorbentes como tirar piedras a un estanque y muchos trabajos artísticos no pretenden mucho más que ese estado autotélico (actividades que producen satisfacción en sí mismas y no sólo por sus resultados). Otras experiencias incorporan componentes narrativos en instalaciones complejas que compiten performativamente con las formas tradicionales del espectáculo cultural.

La variedad y complejidad del arte interactivo está vinculada con la incorporación de los avances tecnológicos en una forma que sea accesible para quienes lo contemplan. Esta relación debe ser analizada para comprender la diversidad que fundamente la interacción de la obra de arte y la complejidad de los procesos entre creadores y espectadores.

\section{Objetivos}

El objetivo general de este trabajo es analizar las posibilidades de la interacción como una nueva forma de expresión artística. Quiere para ello atender a los siguientes objetivos específicos:

a) Exponer una visión general del papel de la tecnología en el arte interactivo.

b) Definir los distintos tipos de interacción y las formas expresivas que de ellos se derivan.

c) Analizar la relación entre los avances tecnológicos y la difusión de las obras.

\section{Metodología}

Para conseguir los objetivos propuestos y aportar una visión global se han revisado ejemplos específicos de importancia en este campo vinculándolos con sus prácticas artísticas. Esta revisión está orientada a formular una definición de los aspectos esenciales, y los fundamentos teóricos para explicar el origen y el sentido de la interacción artística. Se han recopilado diversas fuentes de información a fin de establecer criterios que proporcionen una visión general que ayude a ubicar y 
entender estas formas de expresión. Partiendo de las bases teóricas, se apuntan y enumeran una serie de obras como apoyo a una revisión de los códigos visuales de estas manifestaciones.

Asimismo, se exponen los principios esenciales que conforman la relación entre interacción y arte. Se describen de qué forma esos factores se materializan y cómo condicionan el desarrollo de estas formas de expresión y de qué manera los espectadores, convertidos en usuarios, ven las obras.

\section{Desarrollo}

Para el arte interactivo resulta difícil competir con los videojuegos por conseguir el interés del público. En la exhibición artística no se dispone de tiempo suficiente para aprender ni para leer un manual de instrucciones; es difícil en una relación tan breve crear una experiencia que enganche al espectador (Csikszentmilhayi, 20014).

En el arte interactivo la respuesta de la obra debe ser inmediata, espectacular y comprensible. De ahí que los artistas opten por trabajar con elementos básicos que no requieran apenas aprendizaje. Por ello abundan los sistemas basados en el espejo que reflejan nuestra propia imagen y hacer que nuestros gestos adquieren una mayor complicación, en definitiva, que actúan como un eco de la realidad. Por otra parte, muchos artistas emplean el eco de la imagen original como reflejo amplificado de las acciones del espectador, aumentando la potencia y la sensación de control de manera que nuestros gestos se transforman proporcionando la ilusión de la energía privada de la responsabilidad de los actos reales.

Se analizan a continuación los principios en que se apoyan estas diversas formas de interacción.

\subsection{El espejo}

El hombre deja por donde pasa muestras de su identidad en forma de huellas, sombras y reflejos; estas últimas, la sombra y el reflejo requieren de la presencia 
del referente para que puedan ser percibidas. La identificación del sujeto ante un espejo, esa forma del narcisismo primario del que hablaba Lacan, capacita para objetivar y coordinar las percepciones exteriores con sus sensaciones interiores. Tal identificación promueve la estructura del yo. Primero percibe el reflejo como si no fuera suyo, como una confusión entre uno mismo y el otro, lo identifica y descubre que el reflejo no es otro ser sino una imagen; más adelante comprende que esa imagen mostrada por el espejo es la suya pero invertida. El reflejo le informa de su propia interioridad psicológica.

El diccionario define el espejo como "un material en el que se reflejan los objetos que tenga delante" el espectador, pero también como algo que sirve para señalar las cosas que proporcionan la imagen de algo o para designar "un modelo digno de estudio e imitación" ${ }^{\prime}$. En la literatura y en el arte el espejo ha sido siempre algo más que un artefacto; ha sido una herramienta con la que el artista enfrenta a las personas con su propia imagen. El reflejo posee una vida independiente del sujeto, es capaz de relatar historias en las que el pasado y el futuro suceden simultáneamente y se confunden, desdoblándose y descubriendo sus lados ocultos. Así, la reina bruja de Blancanieves le pregunta: “¿quién es la más bella?”. Los espejos también muestran lo que ha de venir. Nostradamus utilizaba una bola de cristal de cuarzo para ver el futuro y a través de sus reflejos elaborar sus profecías. Y muestran también el pasado como en la tercera entrega de la película Matrix donde cientos de pantallas reflejaban las anteriores visitas de Neo al líder.

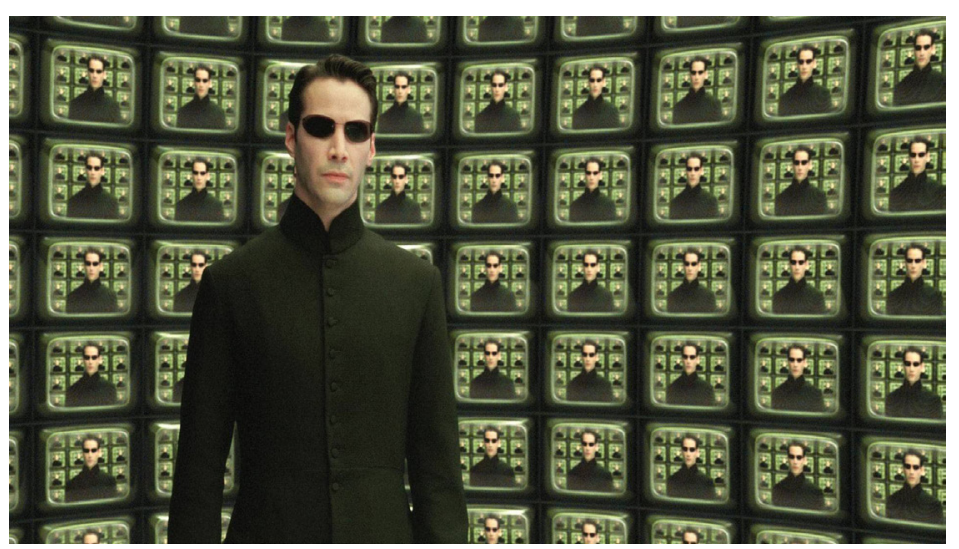

Figura 3: Matrix Reloaded, imagen tomada de stuffpoint.com 
El espejo actúa igualmente como una ventana de comunicación. En La Bella y la Bestia los espejos encantados, a la manera de pantallas informativas, emulan a los actuales dispositivos para videoconferencias, uniendo a personas separadas por la distancia. Draaisma definiría la fotografía como un espejo con memoria ${ }^{6}$. El Rey Sol consolaba su enfermedad al ver reflejada su propia imagen y creer que no estaba sólo. En el Retrato de Dorian Grey, la pintura experimenta los cambios que el protagonista debería sufrir y relata su pasado. Los espejos cóncavos muestran el sentido trágico de la vida española en Luces de Bohemia de Valle Inclán.

Así pues, muchas de las obras de arte interactivo se apoyan en la idea del espejo que sirve como interfaz, como un sistema para la entrada de datos por parte del usuario. Al captar la imagen del espectador, la cámara convierte a la pantalla en un espejo. En sistemas más sofisticados el reflejo no se muestra tal y como ha sido captado, sino mediante sus acciones; de esa forma, el reflejo insinúa acontecimientos y figuras que en realidad no existen. El juego del espacio, el volumen y las sombras, revelan el engaño resultante de plasmar una realidad tridimensional en una superficie plana.

El artista sugiere imágenes que por su extrañeza atrapan a quien contempla sus obras. El reflejo enseña a mirar la realidad de otro modo, a descubrir los espacios atractivos que se parecen a los sueños y que de otra forma no serían tan evidentes. La imagen captada por la cámara forma parte del contexto generado por el ordenador que hace del narcisismo del espectador su principio básico. El hombre reconoce sus manos, sus pies, todo aquello que puede ver, pero adquiere conciencia de sí mismo mediante el reflejo. La conciencia se relaciona de inmediato con la subjetividad.

Si la cámara como interfaz aporta inquietud a la imagen conocida del espejo es porque la relación entre el espectador y su reflejo no es estereoscópica. La cámara y la pantalla como superficie especular carecen del sentido de la profundidad; la imagen reflejada lo es de uno mismo desde otro punto de vista y eso produce además tensión. Sólo este hecho obliga a una reinterpretación de la realidad. El cerebro elimina rápidamente las diferencias hasta igualar lo que ve con lo que debería ver en un intento por identificar las claves más relevantes de la imagen percibida 
sobre la aprendida. El espejo se emplea como una conversación entre el usuario y su representación mediada por la tecnología.

Cuando la imagen visual y el mundo real no coinciden, el cerebro crea una nueva representación mental. Estas capacidades son las que permiten a los usuarios manejarse rápidamente en los entornos virtuales y recodificar sus percepciones de forma inmediata.

Como ejemplo de arte interactivo basado en el espejo y en una imagen transformada de la realidad, cabe señalar las obras de Daniel Rozin ${ }^{7}$. En ellas el espectador ve una representación de sí mismo en una pantalla que, convertida en espejo, transforma la imagen o el espacio según los criterios del artista. En estos trabajos el contenido es la diferencia entre lo real y lo mostrado por la reflexión.

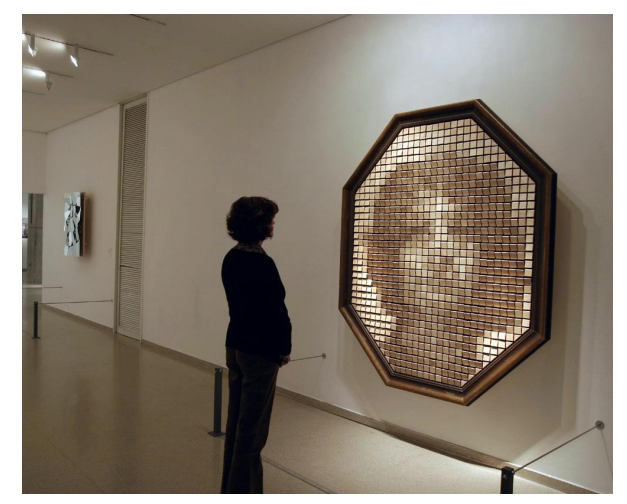

Figura 4: Daniel Rozin. Espejos mecánicos, madera 1999, imagen tomada de suddenexposure. https://www.youtube.com/watch?v=BZysu9QcceM\#t=14 YouTube

Daniel Rozín es autor de la serie, Los espejos mecánicos; su característica principal es la manera en que conforma la imagen reflejada en piezas de madera, un material que convertido en píxel muestra al espectador la contradicción entre la tecnología y los objetos físicos. El espejo, al igual que la unión de una cámara y una pantalla, permite vernos a nosotros mismos tal y como los demás nos ven.

Pero en los trabajos de Rozin y de otros muchos artistas de arte interactivo, los espejos son algo mas, son canales que actúan como transmisores de información. 
Umberto Eco elaboró una clasificación de los espejos según sus propiedades y los distintos reflejos que pueden proporcionar. Distingue entre los de superficie plana y los de superficie curva, los deformantes, los ahumados, los que "congelan" la imagen, etc. Como en los antiguos parques de atracciones, el espejo deformante siempre ha sido, sin más tecnologías, un elemento de gran atracción para el público.

En los espejos deformantes se crean imágenes especulares que pueden ser objeto de interpretaciones semióticas complejas, pero en muchos otros casos, como los anteriormente citados de Daniel Rozin, se crean situaciones que provocan engaños perceptivos tales como hacernos creer que estamos ante un objeto real de madera que es en realidad una imagen especular deformada. En este caso, existen en el espectador principios interpretativos que son ajenos a la imagen especular en sí misma.

Mediante el trabajo de interpretación, el espectador, como sucede con la imagen fragmentada, tiende a reconstruirla y recuperarla para determinar su referente. El público busca y explora el software, las pautas, la posición de la cámara, la deformación del espejo, para descifrar la imagen. Es una tarea de exploración que emplea esa parte más creativa de la mente del público capaz de disfrutar con la búsqueda o simplemente con dejarse llevar por la experiencia o fantasear sobre él contenido.

El artista suele buscar un significado en su obra reflejando la realidad captada por la cámara de manera que el montaje origine, como en los espejos deformantes de los que habla Umberto Eco, una situación abierta a una interpretación semiótica más compleja.

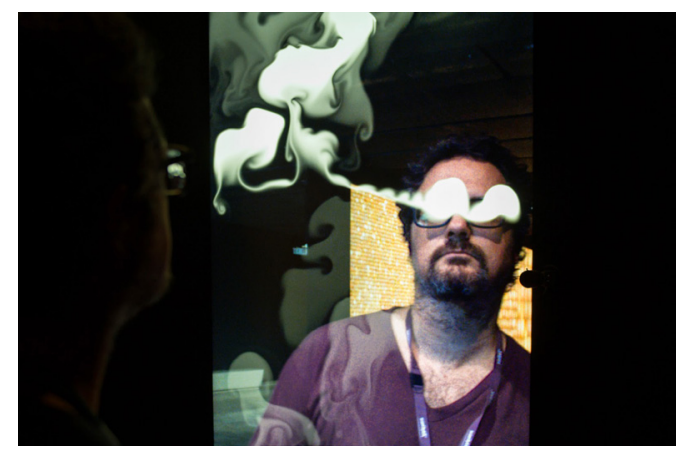

Figura 5: Rafael Lozano-Hemmer: Abstracción Biométrica. Tomada de arte a un click 


\subsection{El eco}

Eco es la repetición de un sonido reflejado por un cuerpo duro; es también cualquier cosa que se repite servilmente, o que está influido por un antecedente o que es devuelto de modo tal que se percibe como distinto de lo originalmente emitido ${ }^{8}$.

Con los conceptos que se desprenden de estas definiciones podemos entender la reflexión y las teorías sobre los espejos deformantes, como un eco de la imagen original. El artista muestra la realidad tal como resulta deformada por sus interpretaciones personales, del mismo modo que el eco transforma lo que hace el espectador en otra cosa. De alguna manera, el eco se percibe con un sonido. Mientras que el reflejo perfecto es un sistema cerrado, la reflexión transformada es un dialogo entre uno mismo y el mundo exterior. El eco tiene una relación obstinada a través de la cual la imagen de uno mismo y su relación con el mundo, pueden ser examinadas, interrogadas y transformadas.

En muchos de los trabajos interactivos se emplea el eco. En ellos la imagen deformada del espectador se convierte en el dispositivo a través del cual se explora la propuesta de realidad artificial del artista. El espectador puede verlo como transformaciones de su propia imagen, como claves para comprender lo representado en la pantalla. Este mundo del que tiene un punto de vista privilegiado, le ofrece una mirada voyeurística para observar los eventos que ocurren al otro lado, despierta la curiosidad y el deseo de entrar en ese mundo virtual, al otro lado del espejo.

Los artistas utilizan el espejo de la pantalla proyectada de sus obras como una inversión de la realidad para proponer, como Lewis Carroll en A través del espejo y lo que Alicia encontró allí, una visión del mundo que no se entiende como «realidad» (tal como lo contemplamos nosotros) sino justamente como lo contrario, como una inversión de la realidad. Como ejemplos de esta modalidad, cabe destacar la instalación Interactive Wall de FlightPhase, que usa la imagen reflejada como sistema de interacción.

DOI: ri14.v13i1.754 | ISSN: 1697-8293 | Año 2015 Volumen 13 Nº 1 | ICONO14 


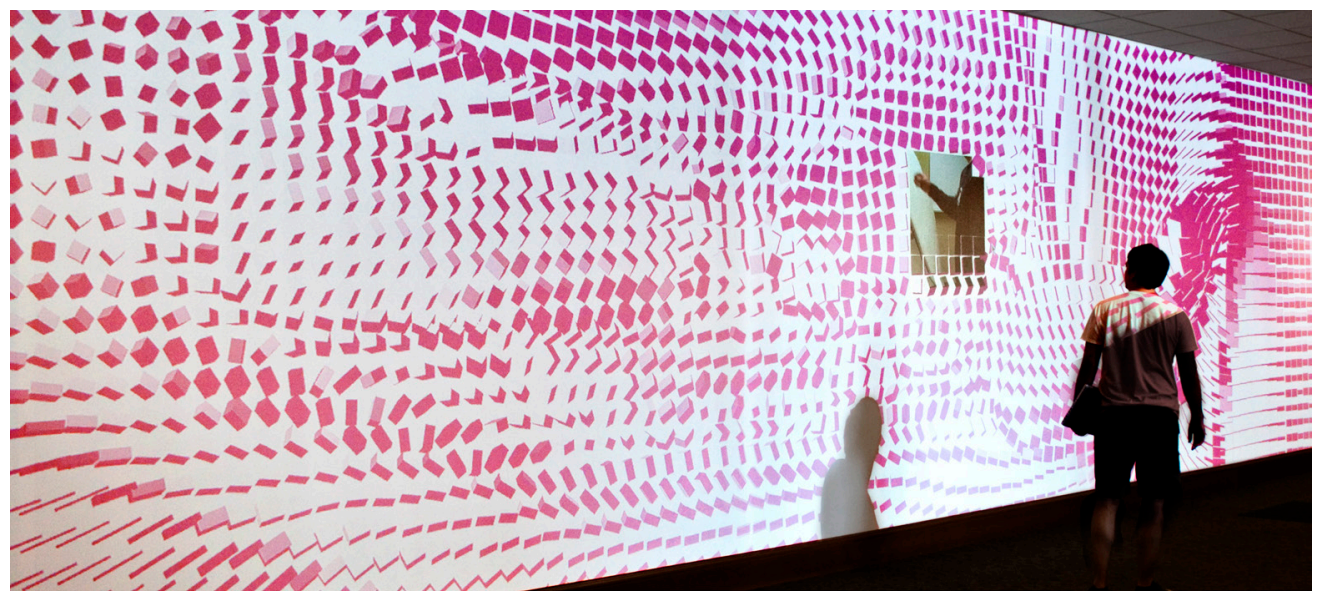

Figura 6: Interactive Wall de FlightPhase. Imagen tomada de creative applications network

Cuando alguien entra en el área interactiva envía una onda a los patrones de la proyección; el sistema hace un gesto de reconocimiento de que cada espectador tiene un impacto en todo el sistema.

\subsection{Potencia y control}

El trabajo de David Rokeby debe entenderse como un interfaz de reconocimiento de los gestos que superponen los fenómenos de la transformación sobre la imagen conocida de uno mismo. Una cámara capta los gestos y los transforma en música. Además de reflejar su imagen, el espectador ve modificado el conocimiento sobre su cuerpo, el fenómeno representado se muestra como un cambio de la representación de sí mismo.

Para mucha gente, la interacción significa "control". La tecnología se emplea para el fortalecimiento del espectador; de esta forma, al mover un brazo suena una música y cuando lo levanta, sube el volumen. Este aumento de energía es la principal atracción de los videojuegos que transforman las decisiones de los jugadores amplificándolas en acciones complejas que determinan cuanto sucede en el mundo virtual. Es la ilusión de la energía privada de la responsabilidad que caracteriza a los actos reales.

ICONO14 | Año 2015 Volumen 13 Nº 1 | ISSN: 1697-8293 | DOI: ri14.v13i1.754 


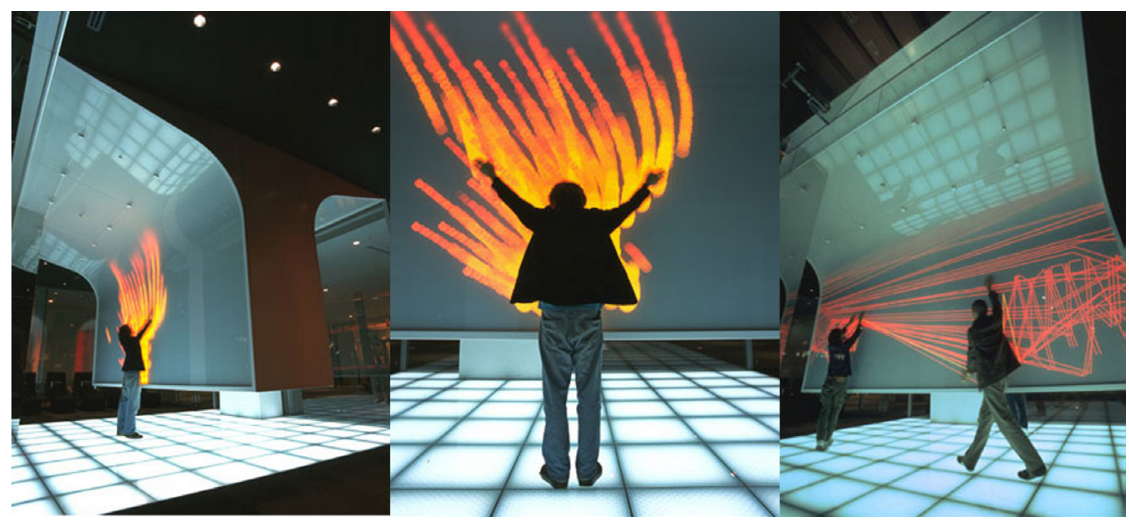

Figura 7: Bloomberg ICE. Marunouchi, Tokyo Station Tokyo 10.2002 Klein Dytham architecture / Toshio Iwai

Quienes experimentan el arte interactivo son espectadores de amplia cultura visual que lo hacen condicionados por las grandes expectativas que despiertan los videojuegos. El artista debe comprender que el arte introduce variables que lo hacen más rico pero también menos ego-gratificante. Si la distorsión de la imagen es muy grande con respecto a la realidad, se pierde el punto de vista del espejo. Cuanta menos distorsión haya, más fácil es para el espectador identificar las respuestas del sistema a sus acciones. El arte debe lograr un equilibrio razonable entre el sentimiento de control que permite su identificación, y la riqueza del comportamiento de respuesta que cierra el sistema.

El público quiere saber si el sistema es realmente interactivo, anhela lo previsible, que se comporte igual ante una misma acción. Cuando el sistema es simple, así lo hace; pero en otros más complejos, capaces de aprender por la repetición de una acción, establecen un patrón y pueden responder con nuevas y diferentes respuestas.

En la obra de Toshio Iwai para Bloomberg ICE expuesta en la estación de Tokio en octubre de 2002 (imagen 7 http://klein-dytham.com/other/bloomberg-ice/), el sistema respondía siempre del mismo modo ante un mismo gesto: reproducía un sonido. El participante repetía la acción y, a la tercera vez se convencía del funcionamiento del sistema. 
Los artistas pueden crear interfaces más complejas y ambiguas sin las limitaciones ni las presiones de los productos comerciales $\mathrm{y}$, sobre todo, capaces de transmitir el particular punto de vista del autor. Los mecanismos perceptivos ofrecen comportamientos inesperados hasta para el propio creador. Es una contradicción entre el deseo de control y la esperanza de la sorpresa.

La complejidad de los trabajos artísticos que hacen uso de la tecnología deja ver su escasa coincidencia con el punto de vista del ingeniero. Estas diferencias residen en el control técnico de la interacción y en el hecho de que el artista pretenda dar satisfacción a su estética interactiva. Sobre estas dificultades, Andrew Stern en un artículo titulado "Por qué los artistas deben programar", señala que el desafío fundamental para quienes trabajan con sistemas interactivos, consiste en crear imágenes, interactuar con el público y pretender que sean comprendidas. En el diálogo entre el participante y el artista se pone cuidado en escuchar lo que el otro comunica, cada interacción produce una regeneración que, si es entendida, provocará una nueva interacción intencionada y así sucesivamente. La capacidad para mantener una conversación correctamente es una habilidad diaria común que todos poseemos y que sin embargo es difícil y compleja de reconstruir con un ordenador.

\section{El interfaz como relación}

Para que el trabajo artístico sea verdaderamente interactivo y pueda llegar a convertirse en un diálogo, es necesario un interfaz capaz de interpretar a los participantes y una programación que gestione la respuesta para una mejora de la experiencia del usuario. Aquellos trabajos que simplifican sus procesos convirtiéndose en lo que Stern ${ }^{10}$ denomina trabajos reactivos o arte del botón, se reducen a instrucciones y comportamientos limitados: "pulsa aquí y mira allí". Para conseguir sus objetivos, los artistas se ven obligados pensar como programadores y conocer las tecnologías de forma que puedan concebir y crear arte verdaderamente interactivo capaz de expresar sus intenciones artísticas.

En la presentación de Nell Breyer sobre la exploración del movimiento pueden verse una compleja manipulación de imágenes captadas por una cámara en tiempo real. En ellos se ignoran los elementos repetidos entre dos fotogramas y quedan 
tan sólo aquellos que cambian con el movimiento. Muestran los magníficos resultados de la combinación de la informática y la búsqueda de imágenes artísticas. Los efectos basados en el contorno mediante la congelación de las imágenes precedentes, conforman auténticos cuadros en movimiento.
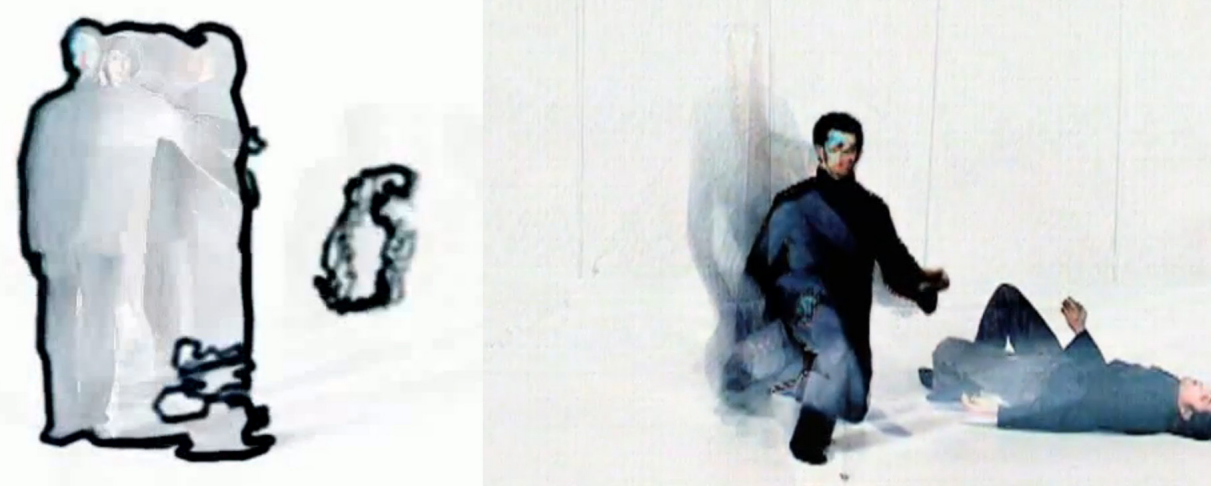

Figura 8: Nell Breyer. Motion Perception. imagen tomada de researchcatalogue.net http://www.researchcatalogue.net/view/11138/11171

El artista interactivo busca, mediante planteamientos sofisticados, atraer a esa parte del cerebro, capaz de dejarse llevar por la aventura y la creatividad. Avances como los propuestos por Nell Breyer abren nuevas posibilidades para lograr estos objetivos y muestran la belleza de que cada proyección sea irrepetible, recordada 0 reconstruida de manera diferente.

Para ello se requieren dispositivos que ayuden a los participantes a crear su propia obra. No se trata de convertir al usuario en artista, no se pretende poner un pedazo de barro para que los visitantes se conviertan, al interactuar con él, en escultores, sino ofrecer una obra abierta que el espectador pueda explorar de manera plenamente interactiva.

El artista pretende para su obra infinitas lecturas pero sin que tal cosa deje sin sentido la presencia de quien en su totalidad o parcialmente la ha creado. En las antiguas propuestas sobre tecnología de videodisco donde las opciones estaban previamente renderizadas, el espectador se limitaba a elegir una u otra, al modo 
que podía leer las diversas alternativas de Rayuela de Cortazar. Por muchas que fueran las posibilidades quedaban siempre limitadas a un número reducido. En cambio, con las nuevas obras que emplean cálculos en tiempo real e inteligencia artificial, las combinaciones son impredecibles, incluso para el propio artista.

Desde los años sesenta los artistas han querido cambiar el punto de vista de los espectadores, haciendo uso para ello de los medios tecnológicos disponibles en cada momento ${ }^{11}$. Su objetivo ha sido que el público participara parque en ello se fundamenta el arte interactivo, una característica que se ha hecho más intensa con la aparición de tecnologías más potentes y accesibles pero que no han supuesto una ruptura con las experiencias anteriores. Gracias a este progreso ha sido posible un significativo incremento de la intervención del público. Al emplear distintos medios se anticipa a la recepción estética que significará su obra para quienes participen en ella. Los primeros trabajos se basaban en lo que ya hemos citado como arte de botón, sensores que producen efectos. Propuestas basadas en el uso del ratón o en pantallas táctiles que no cambian el sentido de la instalación, utilizaban generalmente imágenes pregrabadas en un videodisco.

Obras como las que el artista japonés Toshio Iwai ${ }^{12}$ mostró en el Pabellón de Japón de la Expo de Sevilla, se manejaban con sensores muy simples del mundo real, o como la columna de sonido, Sonicolumn de Jon-Ki-Mok ${ }^{13}$ que controlaba la iluminación directamente con el tacto y posteriormente, con una manivela similar a las de persianas y toldos que permitía girar la columna.

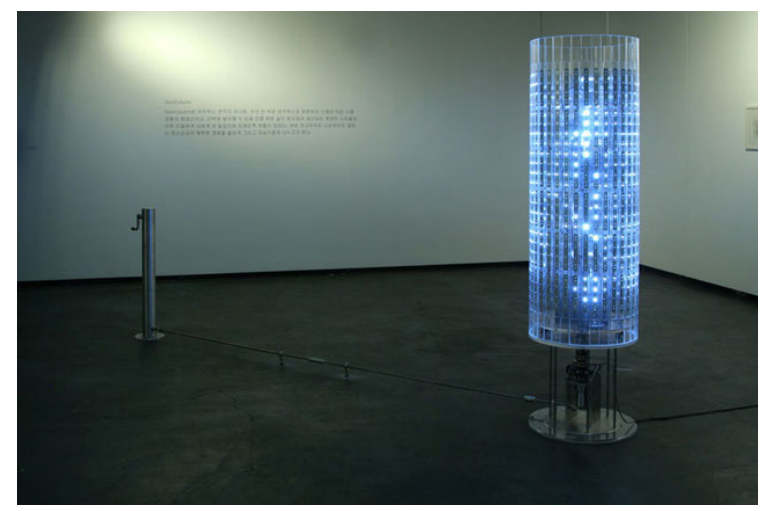

Figura 9: Sonicolumn. Jin-Yo Mok 2006

ICONO14 | Año 2015 Volumen 13 Nº 1 | ISSN: 1697-8293 | DOI: ri14.v13i1.754 
Estos sistemas utilizan objetos cotidianos ajenos a la tecnología, cuya función original ha sido modificada para crear relaciones entre el mundo real y la percepción interactiva. De esta forma, sensores ocultos como detectores de presencia, infrarrojos, baldosas sensibles a la presión, producen efectos en la obra. Trabajos de este tipo, manejados con complejos controles informáticos de dialogo, logran que el espectador se detenga más en la interacción en sí misma.

Con el uso de interfaces invisibles, los autores abandonan las formas de la narración tradicional de manera que la obra aporta un nuevo significado a la interacción y al diseño del propio interfaz que adquiere mayor importancia. Estos planteamientos crean un espacio abierto donde la interacción se apoya en la proximidad antes que en el instrumento utilizado. Esto ha tenido importantes consecuencias para entender el interfaz. En el caso del video, la cámara es, de alguna manera, invisible, pierde su significado y es sustituida por la aplicación en sí misma.

En la obra de Krueger, Videoplace, el sistema combina la imagen obtenida por la cámara con otras imágenes gráficas. El usuario controla veinticinco formas diferentes de interacción entre su imagen en vivo y las ya pregrabadas que pueden ser mezcladas por el ordenador. Krueger cambia las reglas de la reflexión narcisista y permite al usuario modificar las imágenes resultantes como si fueran versiones de ellos mismos. En otro de sus trabajos, un personaje de color verde interactúa con la propia imagen del visitante que para encontrar la lógica del referente, intentará adelantarse y romper los límites de las reglas de la programación. No es sólo un juego entretenido, sino que además pone a prueba la potencia de la relación entre usuario y sistema.

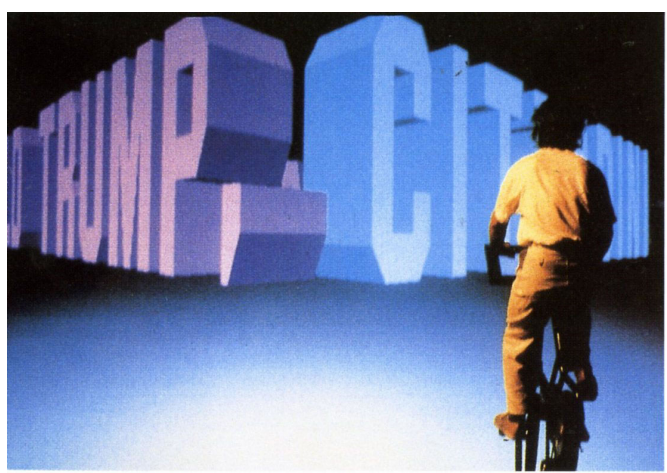

Figura 10: Jeffrey Shaw, «The Legible City», 1988 - 1991, Imagen tomada de vecchiefarabrutte 
En The Legible City, de Jeffrey Shaw, el visitante se mueve pedaleando sobre una bicicleta en una ciudad de letras. El sistema, implementado en 1988, evidencia claramente sus limitaciones gráficas; el cálculo de escenarios virtuales en tiempo real no era entonces suficientemente eficaz para producir un resultado mejor. Puede observarse cómo la elección de un interfaz condiciona al visitante con un particular patrón de conducta que influye en su experiencia con la obra, como ocurre en el mundo real. Así sucede cuando se llega por primera vez a una ciudad; la impresión es muy distinta según las circunstancias en que tal visita se produzca y afecta la apreciación que de ella se obtiene; no es lo mismo si es de noche, si llueve, si se llega paseando, en coche o en un autobús turístico.

Otros trabajos están más basados en la participación que en la interacción. En estos casos, los efectos se consiguen gracias a varios usuarios que interfieren con la obra. Para quienes actúan, se trata de una performance pero, para los espectadores no implicados, es tan sólo un teatro.

Por otra parte, es imprescindible una respuesta eficaz del sistema. Es difícil estimular en el espectador la exploración, la inmersión y el conocimiento de la obra cuando el sistema no reacciona directamente a sus acciones. En cierta medida, la exploración que fundamenta esta forma de arte apela a cualidades deportivas como la ambición y el espíritu de equipo que implican experiencias alternativas de placer y frustración propias de una competición.

Las instalaciones interactivas basadas en la narración no lineal son una evolución de los ejemplos de la tradición oral. El sistema tiene almacenadas las diversas alternativas que, por muchas que puedan ser, son limitadas ya sea por el coste económico o por la complejidad de la producción. El participante es el director y montador de la historia. Son muchas las obras en Internet que han desarrollado esta idea. Jon Weinbren de Imaginary Productions (http://www.imaginary.co.uk) se plantea si la narrativa interactiva es un oxímoron; observa la baja calidad narrativa cuando predomina la interacción, quizá por las diferencias entre el público que busca interacción y el público que busca narración: cuando alguien lee una obra de autor desea algo nuevo, quiere enriquecerse con sus opiniones y puntos de vista, no quiere ver reflejados en el texto sus propias ideas. 
La tecnología abre nuevas posibilidades a la narración interactiva. Para que la interacción funcione en esa actitud narcisista del mundo digital, debe ser más interesante que la propia historia.

La técnica de programación y la mejora de las capacidades de cálculo del ordenador han permitido crear mundos en los que se puede interactuar libremente. Se trata de aplicaciones "orientadas a objeto". Esta narrativa inspirada en los juegos de rol parte de una trama genérica que enmarca la historia, del perfil de las características y la "personalidad" de los protagonistas que intervienen y de reglas que resuelven los encuentros entre ellos. La historia avanza siguiendo estas normas y dependiendo de las interacciones, como en la vida real. Durante toda la historia se mantiene la memoria de las acciones sucedidas, indispensable para tener cierto control sobre el discurso narrativo.

Lamentablemente la fragmentación del contenido no ayuda a entender mejor lo que sucede. Sólo con narraciones muy conocidas el significado adquiere una suerte de sentido social $\mathrm{y}$, en ese caso, el acceso interactivo podría posiblemente añadir nuevos puntos de vista. Los videojuegos basados en una película, operan con unos personajes y una historia que garantizan un mejor comprensión de todo el entramado narrativo. Spiderman puede caminar, correr, trepar, volar por Nueva York, resolver delitos y pelear con supervillanos. Ya lo hemos visto en la película.

La propuesta se convierte en un juego de rol en el que el jugador, inmerso en el papel del protagonista conduce la narración mediante la toma de decisiones. La ventaja para las generaciones educadas en la cultura digital es que no necesitan leer un grueso volumen para introducirse en la historia, su disposición facilita la usabilidad.

Si se quiere una inmersión total como un auténtico Wreeder (lector/escritor), los actores no pueden ser reales sino virtuales y es necesario que puedan modificar sus propiedades. Con las aplicaciones orientadas a objeto, las propiedades asignadas a los personajes, podrán modificarse en cada historia; si me quito el sombrero, tal decisión afectará a lo que suceda a partir de entonces; si llueve, estaré mojado y si decido llevar una maleta, andaré más despacio.

DOI: ri14.v13i1.754 | ISSN: 1697-8293 | Año 2015 Volumen 13 Nº 1 | ICONO14 


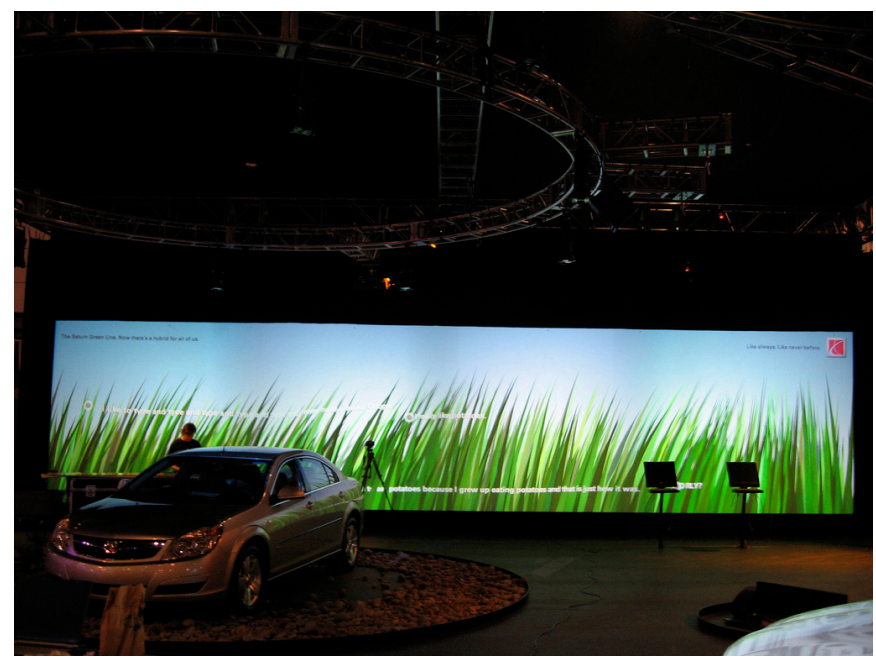

Figura 11: Grass de The Barbarian Group, imagen tomada de roberthodgin.com

La instalación interactiva Grass es un ejemplo en el que aparecen agrupadas las características de eco, potencia y control que han sido señaladas con anterioridad. Esta instalación, obra del Barbarian Group y presentada en el Wired Nexfest, mezcla los tres conceptos fundamentales que maneja el arte interactivo: el espejo, el eco y la ampliación de nuestros actos. Aunque la imagen del visitante no se ve, su intervención queda patente en la hierba como si su reflejo estuviera dentro de la pantalla. Se plasma aquí un concepto de la Gestalt, la relación entre figura y fondo por la que percibimos la presencia de la figura por el espacio gracias a la huella que deja en la hierba.

Grass es un mundo irreal pero su elemento principal, la hierba, tiene funciones de sobra conocidas para que el espectador comprenda el funcionamiento de la obra e interactuar fácilmente con ella. Igualmente, la reacción del sistema es rápida y consistente y proporciona un excelente feedback; ante movimientos iguales produce una reacción que el espectador puede predecir. El enorme mural de hierba es el aspecto estético percibido por el visitante, pero su comportamiento define la poética de la obra, mientras la tecnología de programación y de captura del movimiento de los visitantes, permanece oculta. El espectador abandona su condición de contemplador pasivo para integrarse en la propia dinámica creativa de la propuesta. Mantiene una doble perspectiva exógena y endógena al mismo tiempo, actuando simultáneamente como observador y participante activo, como sujeto y 
objeto, en una alternancia con el sistema. El diseño tiene presente al cuerpo del observador y considera su comportamiento físico por lo que, al contrario que otras obras de arte interactivo, da más importancia a la interacción que a la narración. La obra de arte electrónico interactivo exhorta el paso desde la teoría estética clásica (Giannetti, 1999, 6), centrada en el objeto de arte hacia una nueva teoría que tiene como punto de referencia principal al interactor ${ }^{14}$.

Cuando, como en este caso, se consigue un interfaz capaz de relacionar los comportamientos de la hierba con los movimientos del participante en el mundo real, se produce una fascinación que lleva a un alto grado de inmersión. Si el visitante sale del área de acción de la cámara que capta sus movimientos, termina la experiencia. La elección de los mismos se vincula a su vez con el aspecto poético de la obra y con la orientación didáctica para una mejor interacción.

Un último aspecto que cabe señalar tiene que ver con los ámbitos en que estas obras se difunden. Por ahora se exponen en galerías de arte como si fueran cuadros convencionales, estáticos, pero también en ferias de tecnología para demostrar la capacidad de investigación de las empresas involucradas. A los galeristas les interesa un arte que pueda comercializarse. Animados por el mismo espíritu que llevó a Edison a inventar sólo aquello que pudiera proporcionar beneficios, consideran que las obras que no pueden venderse, carecen de sentido. Este aspecto es particularmente complejo en una forma de expresión que no produce objetos artísticos en el sentido tradicional y que precisa para su difusión canales alternativos a las galerías y los museos

\section{Conclusiones}

1. En esta forma de expresión, los artistas están obligados a pensar como programadores y tener un conocimiento de las tecnologías que les permita concebir y crear arte verdaderamente interactivo y poder expresar así sus intenciones artísticas. Son necesarios enormes esfuerzos en el desarrollo técnico para solventar detalles de gran importancia para la obra artística y que son muchas veces imperceptibles. 
2. El arte interactivo está buscando tanto un lenguaje propio como un espacio para su difusión. El arte interactivo no debe limitarse a estos espacios y ha de llegar a ser parte de la ciudad, de la arquitectura, ha de integrarse para interactuar y experimentar en lugares de encuentro. El nuevo espacio digital al que han contribuido la universalización de los dispositivos electrónicos ha convertido el entorno urbano en el ámbito para la difusión de estas manifestaciones artísticas.

3. La obsolescencia de la tecnología ha hecho que las manifestaciones de arte interactivo sean efímeras y se vean como anticuadas. Los contenidos envejecen tan rápido como lo hace la tecnología. Del mismo modo que la difusión, el arte interactivo necesita de sistemas de almacenamiento que puedan conservar y recuperar propuestas que dependen siempre de la tecnología de cada momento. Difícilmente podrá preservarse su capacidad interactiva si no se desarrollan procedimientos y técnicas que puedan garantizar la existencia de los dispositivos que permitieron su creación y exposición.

4. El arte interactivo requiere de la participación de artistas y técnicos que contribuyen a la realización de una obra colaborativa. No es fácil de focalizar en un único creador la autoría de propuestas en las que, por otra parte, es necesaria la participación de los usuarios para su funcionamiento. El concepto de autor ligado a la obra tradicional, ha de ser revisado porque dificulta la compresión y el análisis de las nuevas formas expresivas del arte interactivo.

5. Las obras interactivas requieren ser comprendidas por los usuarios desde el primer momento porque su exposición no permite ningún periodo de aprendizaje. Por ello muchas de ellas recurren al reflejo y a la potenciación de las acciones porque no precisan de una instrucción previa. La potenciación de los actos, emplea la tecnología para el fortalecimiento del espectador, la ilusión de la energía privada, de la responsabilidad de los actos reales. Sin duda esto afecta al contenido de las propuestas, a su forma de presentación y a la complejidad de su interacción. 


\section{Notas}

[1] Nam June Paik en PÉREZ ORNIA, José Ramón. (1991) El arte del vídeo. Introducción a la historia del vídeo experimental. Barcelona: RTVE Ediciones del Serbal. p. 33.

[2] ECO, Umberto. (1979) Obra abierta. Barcelona: Ariel.

[3] Ya en 2003 Ars Electronica se publicitaba con un lema "Code: The Language of Our Time"

[4] CSIKSZENTMILHAYI, Mihaly. (2001) Ocio y Desarrollo, Potencialidades del ocio para el desarrollo humano. y otros. Bibao: Universidad de Deusto.

[5] Diccionario de la Real Academia. http://www.rae.es

[6] DRAAISMA, D. (1988) Las metáforas de la memoria: Una historia de la mente. Madrid: Alianza Editorial.

[7] http://www.smoothware.com/danny/ [consulta septiembre 2006]

[8] Diccionario de la Real Academia Española. http://www.rae.es

[9] http://www.interactivestory.net/papers/deeperconversations.html [consulta julio 2014]

[10] http://www.interactivestory.net/papers/deeperconversations.html [consulta julio 2014]

[11] POPPER, F. (1989) Arte, acción y participación. Madrid: Akal.

[12] Puede verse un vídeo de sus obras en Metrópolis 28.07.2010 min 25:41. http://www.rtve.es/ television/20100728/arte-interactivo-1994/342400.shtml

[13] http://geneo.net/sonicolumn/ [Consulta diciembre 2006]

[14] Puede verse un vídeo de la instalación en funcionamiento en http://portfolio.barbariangroup.com/nextfest/video.html y un vídeo de la última feria de Nestfest de 2006 de Nueva York con otros trabajos presentados en http://www.youtube.com/watch?v=i_-N3DNNH4U

\section{Referencias}

Candy, L; Edmons, E.A. (2002). Explorations in Art and Technology. Nueva York: Springer.

Costas, A. Perseguido por Eco, Narciso llega al 2000. Recuperado de http://www. apdeba.org/wp-content/uploads/032000costas.pdf

Csikszentmilhayi, M. (1992). Creatividad, El fluir y la psicología del descubrimiento y la invención. Barcelona: Paidós.

Csikszentmilhayi, M. (2001). Y otros. Ocio y desarrollo, Potencialidades del ocio para el desarrollo humano. Bilbao: Universidad de Deusto.

Csikszentmilhayi, M. (1998). Aprender a fluir. Barcelona: Kairós. 
Dinkla, S. The History of the Interface in Interactive Art. Recuperado de http:// www.kenfeingold.com/dinkla_history.html

Dor, J. (1994). Introducción a la lectura de Lacan. Barcelona: Gedisa.

Eco, U. (1985). Obra abierta. Barcelona: Planeta Agostini.

García Márquez, G. (1976). “Diálogo del espejo" en Ojos de perro azul. Barcelona: Plaza y Janés.

Gubern, R (2001). “Del rostro al retrato" en Anàlisi no 27 Imatge $i$ Coneixement. Barcelona: Universitat Autónoma.

Grau, 0. Immersion and Interaction. From circular frescoes to interactive image spaces. Recuperado de http://www.medienkunstnetz.de/themes/overview_ of_media_art/immersion/scroll/

Huhtamo, E. (2002). Interactive art is a very recent phenomenon. It is still in its infancy. It will take a long time for it to mature as an Artform. Recuperado de http://www.maryflanagan.com/courses/2002/web/SevenWays.html

Huhtamo, E. (2006). Elementos de pantallalogía. Recuperado de http://www. miradas.eictv.co.cu/index.php?option=com_content\&task=view\&id=475\&Item $\mathrm{id}=89$ \&lang=es

Kac E. Interactive art on the internet. Recuperado de http://www.ekac.org/ InteractiveArtontheNet.html

Rush, M. (2005). New media in Art. Londres: Thames \& Hudson.

Papini, G. (1984). El espejo que huye. Madrid: Siruela.

Paul, C. (2003). Digital Art. Londres: Thames \& Hudson.

Popper, F. (2007). From Technological to Virtual Art. Massachusetts: The MIT Press. Popper, F. (1989). Arte, acción y participación. Madrid: Akal.

Rokeby,D. Transforming Mirrors: Subjectivity and Control in Interactive Media. Recuperado de http://homepage.mac.com/davidrokeby/mirrors.html 